\title{
Pengaruh Pelayanan Terhadap Kepuasan Masyarakat Di Bagian Haji Dan Umrah Kantor Kementerian Agama Kota Pekanbaru
}

\author{
Zulkifli \\ Fakultas Agama Islam Universitas Islam Riau (UIR) Pekanbaru \\ Jl Kaharuddin Nasution No. 113 Perhentian Marpoyan Pekanbaru 28284 \\ e-mail : zulkifli_rusby@fis.uir.ac.id
}

\begin{abstract}
Abstrak: Penelitian ini dilatarbelakangi oleh banyaknya jumlah masyarakat yang datang ke Bagian Haji dan Umrah Kantor Kementerian Agama Kota Pekanbaru. Salah satu faktor yang menyebabkan banyaknya masyarakat yang datang adalah faktor pelayanan dan kepuasan masyarakat. Adapun rumusan masalah dari penelitian ini adalah apakah pelayanan berpengaruh terhadap kepuasan masyarakat di Bagian Haji dan Umrah Kantor Kementerian Agama Kota Pekanbaru. Tujuan dari penelitian ini adalah untuk mengetahui Pengaruh pelayanan terhadap kepuasan masyarakat di Bagian Haji dan Umrah Kantor Kementerian Agama Kota Pekanbaru. Sementara subjek dalam penelitian ini adalah masyarakat yang datang di Bagian Haji dan Umrah Kementerian Agama Kota Pekanbaru. Sedangkan objek pengaruh pelayanan terhadap kepuasan masyarakat. Sumber data yang digunakan dalam penelitian ini adalah sumber data primer dan sekunder. Teknik pengambilan sampel pada penelitian ini incidental sampling, sedangkan teknik pengumpulan data yang digunkan ialah angket. Analisis data menggunakan metode kuantitatif. Dalam menganalisis data digunakan analisis regresi linier sederhana sedangkan dimana proses perhitungannya menggunakan SPSS for Windows Versi 23. Sampel penelitian ini sebanyak 91 orang. Hasil penelitian ini diketahui bahwa terdapat pengaruh yang signifikan antara pelayanan terhadap kepuasan masyarakat, ini diketahui dari $t_{\text {hitung }}(12,169)>t_{\text {tabel }}(1,986)$ variabel $X$ (pelayanan) berpengaruh terhadap variabel Y (kepuasan masyarakat). sedangkan pengaruh pelayanan terhadap kepuasan masyarakat memiliki hubungan yang kuat ini diketahui dari nilai koefisien korelasi sebesar 0,790. Sedangkan nilai koefisien determinasi sebesar 0,625 artinya pengaruh pelayanan terhadap kepuasan masyarakat sebesar $62,5 \%$ sedangkan sisanya sebesar 37,5\% di pengaruhi oleh variabel lain.
\end{abstract}

Kata Kunci : Pelayanan, Haji dan Umrah, Kepuasan, Masyarakat 


\section{PENDAHULUAN}

Salah satu tanda dan bukti bahwa pemerintah itu mengabdi kepada rakyatnya adalah dapat dilihat sampai seberapa jauh pelayanan yang diberikan kepada masyarakat itu baik. Demikian pula salah satu wujud suatu tata kepemerintahan yang baik, demokratis dan amanah bisa diamati dari cara pemerintahan memberikan pelayanan kepada publik. Pengertian baik demokratis dan amanah itu ialah sesuai dengan keinginan rakyat bukan sematamata keinginan penguasa pemerintah.

Pelayanan Publik adalah semua kegiatan yang pemenuhannya harus dijamin, diatur dan diawasi oleh pemerintah, karena itu diperlukan untuk perwujudan dan perkembangan saling ketergantungan sosial dan pada hakikatnya, perwujudannya sulit terlaksana tanpa campur tangan kekuatan pemerintah. Instansi Pemerintah merupakan organisasi yang berisi kumpulan orang-orang yang dipilih secara khusus untuk menjalankan tugas negara sebagai bentuk pelayanan terhadap orang banyak. Tujuan instansi pemerintah dapat dicapai apabila mampu mengolah, menggerakkan dan menggunakan sumber daya manusia yang dimilik secara efektif serta efisien.

Masyarakat membutuhkan pelayanan untuk memenuhi berbagai macam kubutuhan yang tidak dapat dipenuhi sendiri, bahkan secara ekstrim dapat dikatakan bahwa pelayanan tidak dapat dipisahkan dengan kehidupan manusia. Pelayanan yang baik sangatlah penting karena bentuk pelayanan yang baik dapat menarik perhatian dari masyarakat, pelayanan yang dikelola dengan baik diharapkan dapat memenuhi harapan masyarakat. Karena masyarakat memiliki peran besar untuk perbandingan standar evaluasi kepuasan maupun kualitas. Kepuasan masyarakat merupakan perbandingan antara keyakinan masyarakat yaitu masyarakat itu sendiri yang akan diterimanya dengan kualitas layanan yang diterimanya dalam bentuk kinerja.

Berdasarkan hasil pengamatan peneliti beranggapan bahwa terdapat beberapa keluhan yang dirasakan oleh masyarakat. Seperti dalam pengurusan surat Rekomendasi umrah, yang mana surat Rekomendasi umrah wajib dikeluarkan oleh Kantor Kementerian Agama Kota Pekanbaru, bagi Masyarakat yang berumur di atas 12 Tahun dan di bawah 50 Tahun. Dan kurangnya info kepada masyarakat bahwa surat Rekomendasi harus ditanda tangan yang bersangkutan langsung, dan membawa foto copy KTP. Kurangnya informasi tentang.

Daftar haji sehingga masyarakat yang datang masih belum memenuhi persyaratan, dan sering jaringan Siskohat se-Indonesia putus menyebabkan masyarakat menunggu lama dan mungulanng foto dan sidik jari beberapa kali. Berdasarkan hasil pengamatan singkat peneliti diatas, maka peneliti tertarik untuk meneliti lebih lanjut bagaimana pengaruh pelayanan terhadap kepuasan masyarakat bagian Haji dan Umrah Kantor Kementerian Agama Kota Pekanbaru. Berikut ini adalah data jamaah haji Sekota Pekanbaru Tahun 2014 - 2018 pada tabel 1. 
Tabel 1 : Data Jamaah Haji Tahun 2014 - 2018

\begin{tabular}{|c|c|c|}
\hline No & Tahun & Jumlah Jamaah \\
\hline 1 & 2014 & 2.456 \\
\hline 2 & 2015 & 2.807 \\
\hline 3 & 2016 & 2.562 \\
\hline 4 & 2017 & 3.272 \\
\hline 5 & 2018 & 3.407 \\
\hline
\end{tabular}

Sumber : Data Olahan 2019.

Peneliti memiliki asumsi bahwa suatu pelayanan yang bermutu dan berkualitas sangat dipengaruhi oleh berbagai aspek, yaitu seberapa besar dukungan dari sumber daya manusia serta organisasinya, dan bagaimana proses tata pelaksanaannya dilakukan. Dalam proses pelaksanaan pelayanan inipun, peneliti melihat adanya beberapa kelemahan, seperti : kurangnya respon, baik respon terhadap keluhan, aspirasi, maupun harapan masyarakat yang tidak jarang diabaikan; kurangnya koordinasi dari berbagai pihak pelaksana pelayanan yang kurang dalam berkordinasi; kurangnya tempat duduk bagi masyarakat yang datang, sering tidak hadirnya karyawan yang bertugas, dan masih rendahnya kualitas birokrasi dimana pelayanan pada umumnya dilakukan melalui proses yang terdiri dari berbagai level, sehingga menyebabkan penyelesaian pelayanan yang terlalu lama.

Setelah dilihat dari uraian latar belakang masalah tersebut di atas, maka dapat dikemukakan rumusan masalah dalam penelitian ini adalah bagaimana Pengaruh Pelayanan Terhadap Kepuasan Masyarakat di Bagian Haji dan Umrah Kantor Kementerian Agama Kota Pekanbaru? Adapun tujuan dalam penelitian ini adalah untuk mengetahui Pengaruh Pelayanan Terhadap Kepuasan Masyarakat di Bagian Haji dan Umrah Kantor Kementerian Agama Kota Pekanbaru.

\section{TINJUAN PUSTAKA}

\section{Teori Pelayanan dan Kepuasan} Pengertian Pelayanan

Secara etimologi, layanan adalah perbuatan menyediakan segala apa yang diperlukan orang lain. Aktifitas layanan yang tidak hanya sebatas memenuhi kebutuhan pemakai layanan. Meski ada nilai tambahan pada aktifitas tersebut. Kemudian penciptaan nilai bagi kepuasan pelanggan akan menjadi sebuah "Pekerjaan Rumah" bagi para pembisnis. ( Zulkifli, Jurnal Rumpun Ekonomi Syariah, Vol 1, 2018:3). Menurut Keputusan Menteri PAN No. 63 / KPR / M.PAN/ 2003 Tentang Pedoman Umum Penyelenggaraan Pelayanan Publik, bahwa Pelayanan Publik adalah segala kegiatan pelayanan yang dilakukan oleh penyelenggaraan pelayanan publik sebagai upaya pemenuhan kebutuhan penerima pelaksanaan ketentuan peraturan pelayanan prima kepada masyarakat yang merupakan perwujudan kewajiban aparatur pemerintah sebagai abdi negara.

\section{Pengertian Kepuasan}

Menurut Burhanuddin (2010:16) lembaga keuangan dapat dibagi menjadi dua yaitu:

a. Memperkecil kesenjangan-kesenjangan yang terjadi antara pihak manajemen dan pelanggan.

b. Perusahaan harus mampu membangun komitmen bersama untuk menciptakan 
visi didalam memperbaiki proses pelayanan.

c. Memberikan kesempatan kepada pelanggan untuk menyampaikan keluhan. Dengan membentuk sistem saran dan kritik. (Lupiyadi dan Hamdani, 2012:192).

\section{Strategi Kepuasan Pelanggan}

Dalam Kamus Besar Bahasa Indonesia kata strategi mempunyai beberapa makna, yaitu ilmu dan seni menggunakan semua sumber daya bangsa-bangsa, ilmu dan seni memimpin bala tentara untuk menghadapi musuh dalam perang dalam kondisi yang menguntungkan, rencana yang cermat mengenai kegiatan untuk mencapai sasaran. Bahwa kepuasan pelanggan merupakan strategi jangka panjang yang membutuhkan komitmen, baik menyangkut dana maupun sumber daya manusia. Ada beberapa strategi yang dapat dipadukan untuk meraih dan meningkatkan kepuasan pelanggan:

a. Strategi pemasaran berupa Relationship Marketing, yaitu strategi dimana transaksi pertukaran antara pembeli dan penjual berkelanjutan tidak berakhir setelah menjualan selesai.

b. Strategi superior customer service, yaitu pelayanan yang lebih baik dari pada pesaing. Hal ini membutuhkan dana yang besar, kemampuan sumber daya manusia, dan usaha gigih agar dapat tercipta suatu pelayanan yang superior.

c. Strategi unconditional guarantees strategi ini berintikan komitmen untuk memberikan kepuasan kepada pelanggan yang pada gilirannya komitmen untuk memberikan kepuasan kepada pelanggan yang pada gilirannya akan menjadi sumber dinamisme penyempurnaan mutu produk atau jasa dan kinerja persahaaan.

d. Strategi penanganan keluhan yang efisien penanganan kelihan memberikan peluang untuk merubah seseorang pelanggan yang tidak puas menjadi pelanggan produk perusahaan yang puas (atau bahkan menjadi pelanggan yang abadi).

e. Strategi peningkatan kinerja perusahaan ,meliputi beberapa upaya seperti melakukan pemantauan dan pengukuran kepuasan pelanggan secara berkesinambungan, memberikan pendidikan dan pelatihan menyangkut komunikasi, salesmanship, dan publik relations kepada pihak manjemen dan kariawan memasukkan unsur kemampuan untuk memuaskan pelanggan (yang penilainnya bisa didasarkan pada suvei pelanggan) kedalam sistem penilaian prestasi kariawan, dan memberikan empowerment yang lebih besar kepada para karyawan dalam melaksanakan tugasnya.( Tjiptono, 2008:45).

\section{Pengertian Haji}

Secara lughawi (bahasa), haji berarti menyengaja atau menuju dan mengunjungi. Menurut etimologi Bahasa Arab kata haji mempunyai arti qashd, yakni tujuan, maksut, dan menyengaja. Menurut istilah syara' haji ialah berkunjung kebaitullah untuk melakukan beberapa amalan thawaf, sa'i, dan wukuf diarafah serta amalan lainnya pada masa tertentu demi memenuhi panggilan Allah SWT dan mengharap rida-Nya.

\section{METODE}

Penelitian lapangan ialah penelitian yang dilakukan dengajalan mendatangi lokasi atau tempat penelitian, minsalnya perusahaan, rumah tangga, sawah-sawah 
atau tempat lainnya. Jenis penelitian yang digunakan pada penelitian ini adalah jenis penelitian kausalitas, yaitu jenis penelitian yang disusun untuk meneliti kemungkinan adanya hubungan sebab-akibat antar variabel. penelitian ini akan berlangsung dibagian Haji dan Umrah Kantor Kementerian Agama Kota Pekanbaru. Dalam penelitian ini yang dijadikan populasi adalah jumlah masyarakat yang datang pada Bagian Haji dan Umrah Kantor Kementerian Agama Kota Pekanbaru sebanyak 91 masyarakat.

Dan teknik pengambilan sampel menggunakan incidental sampling, Subjek penelitian ini adalah masyarakat yang datang ke Bagian Haji dan Umrah Kantor Kementerian Agama Kota Pekanbaru, Objeknya adalah pengaruh pelayanan terhadap kepuasan masyarakat Bagian Haji dan Umrah Kantor Kementerian Agama Kota Pekanbaru. Sumber data

\section{Uji Validitas}

Pengukuran validitas dilakukan dengan menggunakan rumus Corrected Item Total Correlation dengan taraf signifikan 5\% $(\alpha=0,05)$ artinya suatu item dianggap valid jika berkorelasi signifikan terhadap skor total. Diketahui nilai $r$ tabel (distribusi $r$ tabel) dengan jumlah sampel sebanyak 91 dan dengan taraf signifikansi 5\% $(0,05)$ yaitu sebesar 0,204 (lihat tabel rproductmoment) dan nilai ini dibandingkan dengan nilai $r$ hitung. Sehingga seluruh item-item variabel dinyatakan valid dan layak untuk dianalisis.

\section{Uji Reliabilitas}

Uji reliabilitas digunakan teknik Cronbach's Alpha dimana instrument dapat yang digunakan adalah Data Primer dan Data Sekunder. Teknik Pengumpulan Data menggunakan Angket, Wawancara, Dokumentasi. Pengolahan data secara umum dilaksanakan melalui tahap memeriksa (editing), proses pemberian identitas (coding) dan proses pembeberan (tabulating).

\section{Analisis Data}

Teknik Analisis Data

Metode yang digunakan dalam penelitian ini adalah metode kuantitatif. Metode ini digunakan untuk menganalisis secara statistik guna melakukan uji penelitian terhadap data-data yang diperoleh dengan menggunakan analisis regresi linier sederhana. Angket yang digunakan dalam penelitian ini menggunakan skala lima alternatif, maka terlebih dahulu data kuesioner yang sudah berhasil dikumpulkan akan dilakukan pengujian terlebih dahulu.

dikatakan handal atau reliabilitas bila memiliki koefisien kehandalan sebesar $>0,6$. Berdasarkan uji validitas dengan menggunakan korelasi moment dan uji reliabilitas menggunakan cronbach's alpha di atas dapat disimpulkan bahwa 24 butir pernyataan tentang pengaruh pelayanan terhadap kepuasan masyarakat bagian haji dan umrah kantor Kementerian Agama Kota Pekanbaru dinyatakan valid dan reliable untuk mengukur variabel.

\section{Analisis Regresi Linear Sederhana}

Hasil perhitungan analisis regresi linier berganda melalui SPSS for Windows versi23.0, maka diperoleh nilai-nilai untuk variabel bebas dan variabel terikat dapat dilihat pada tabel berikut : 
Tabel 2 : Analisis Regresi Linear Sederhana

Coefficients $^{a}$

\begin{tabular}{|c|c|c|c|c|c|}
\hline \multirow[b]{2}{*}{ Model } & \multicolumn{2}{|c|}{$\begin{array}{c}\text { Unstandardiz } \\
\text { ed } \\
\text { Coefficients }\end{array}$} & \multirow{2}{*}{\begin{tabular}{c|}
$\begin{array}{c}\text { Standardize } \\
\mathrm{d}\end{array}$ \\
Coefficients \\
Beta \\
\end{tabular}} & \multirow[b]{2}{*}{$\mathrm{t}$} & \multirow[b]{2}{*}{ Sig. } \\
\hline & B & $\begin{array}{l}\text { Stld. } \\
\text { Error }\end{array}$ & & & \\
\hline $1 \quad{ }^{\text {(Constan }}$ & 3.097 & 2.880 & & 1.075 & .285 \\
\hline $\begin{array}{l}\text { Pelayana } \\
\mathrm{n}\end{array}$ & .649 & .053 & .790 & 12.169 & .000 \\
\hline
\end{tabular}

a. Dependent Variable: Kepuasan

Sumber: Data Olahan SPSS Versi 23.0.

Arti angka-angka dalam persamaan regresi linier sederhana di atas adalah:

a. Nilai konstanta (a) sebesar 3.097 Artinya adalah apabila variabel pelayanan diasumsikan nol (0), maka Kepuasan masyarakat. Bernilai 3.097.

b. Nilai koefisien regresi linier sederhana variabel pelayanan (X) sebesar 0.649 Artinya adalah bahwa setiap peningkatan faktor pelayanan sebesar $1 \%$ maka akan meningkatkan Kepuasan masyarakat. (Y) sebesar 0.649. Karena nilai koefisien bernilai positif, maka dapat dikatakan bahwa faktor pelayanan berpengaruh positif terhadap kepuasan jamaah (Y).

\section{Uji Parsial (Uji-t)}

Uji-t dilakukan untuk mengetahui ada atau tidaknya pengaruh variabel bebas terhadap variabel terikat dengan menggunakan Uji Parsial (Uji-t) dengan menggunakan bantuan komputer program SPSS for Windows versi23.0 maka dapat dilihat tabel berikut:

\section{Tabel 2 : Perhitungan Uji-t}

\begin{tabular}{|c|c|c|c|c|c|}
\hline \multirow[b]{2}{*}{ Model } & \multicolumn{2}{|c|}{$\begin{array}{c}\text { Unstandardized } \\
\text { Coefficients }\end{array}$} & \multirow{2}{*}{$\begin{array}{c}\text { Standardize } \\
\mathrm{d} \\
\text { Coefficients }\end{array}$} & \multirow[b]{2}{*}{$\mathrm{T}$} & \multirow[b]{2}{*}{ Sig. } \\
\hline & B & Std. Error & & & \\
\hline $1 \quad$ (Constant & 3.097 & 2.880 & & 1.075 & .285 \\
\hline Pelayanan & .649 & .053 & .790 & $\begin{array}{r}12.16 \\
9\end{array}$ & .000 \\
\hline
\end{tabular}

a. Dependent Variable: Kepuasan

Sumber: Data Olahan SPSS Versi 23.0 
Maka secara parsial dapat diketahui bahwa variabel bebas faktor pelayanan (X) berpengaruh secara signifikan terhadap kepuasan (Y) masyarakat bagian haji dan umrah Kantor Kementerian Agama Kota Pekanbaru dengan nilai sebesar 12.169.

\section{Koefisien Korelasi}

Nilai R menunjukkan korelasi antara variabel independen pelayanan (X) dengan variabel dependen kepuasan (Y). Dari tabel diatas diketahui nilai $\mathrm{R}$ sebesar 0,790 atau sebesar 79\% ada hubungan yang kuat dari faktor pelayanan terhadap kepuasan masyarakat di Bagian Haji dan Umrah Kantor Kementerian Agama Kota Pekanbaru, dimana nilai keeratan hubungannya adalah sebesar 79\%.

\section{Koefisien Determinasi}

Diketahui nilai Adjusted $R$ Squaresebesar 0.625, artinya pengaruh faktor pelayanan terhadap kepuasan masyarakat di Bagian Haji dan Umrah kantor Kementerian Agama Kota Pekanbaru sebesar 62,5\%, sedangkan sisanya sebesar $37,5 \%$ dipengaruhi oleh variabel lain yang tidak dimasukkan dalam penelitian ini.

\section{PEMBAHASAN}

Penelitian ini merupakan analisis regresi linier sederhana, dimana hanya ada satu variabel bebas atau independen (X) yang mempengaruhi variabel terikat atau dependen (Y). Berdasarkan hasil penelitian diatas diketahui bahwa pelayanan mempengaruhi terhadap kepuasan masyarakat pelayanan terdiri dari beberapa bagian seperti kehandalan (reliability) meliputi pelayanan yang akurat, sopan dan ramah, daya tanggap (responsiveness) meliputi mendengar, mengatasi keluhan dan menyampaikan pelayanan secara cepat, jaminan (assurance) meliputi kemampuan mencangkup pengatahuan kopetensib dan menimbulkan rasa aman, empati (empathy) meliputi meminta maaf atas kesalahan layanan dan kemudahan dalam menjalin komunikasi yang baik, berwujud (tangible) meliputi penampilan fasilitas fisik dan berbusana muslim.

Dan berdasarkan uji hipotesis diketahui bahwa;

1) Nilai konstanta (a) sebesar 3.097 Artinya adalah apabila variabel pelayanan diasumsikan nol (0), maka kepuasan masyarakat bagian haji dan umrah Kantor Kementerian Agama Kota Pekanbaru bernilai 3.097. Nilai koefisien regresi linier sederhana variabel pelayanan (X) sebesar 0.649 Artinya adalah bahwa setiap peningkatan faktor pelayanan sebesar 1\% maka akan meningkatkan kepuasan masyarakat bagian haji dan umrah Kantor Kementerian Agama Kota Pekanbaru (Y) sebesar 0.649. Karena nilai koefisien bernilai positif, maka dapat dikatakan bahwa faktor pelayanan berpengaruh positif terhadap kepuasan masyarakat (Y).

2) Terdapat pengaruh yang signifikan antara faktor pelayanan terhadap kepuasan masyarakat bagian haji dan umrah Kantor Kementerian Agama Kota Pekanbaru Hal ini dapat diketahui dari nilai thitung (12.169) lebih besar dari tabel $(1,986)$ atau 12.169> 1,986. Ini juga dapat dilihat dari nilai signifikan (Sig.) sebesar $0,000<0,05$ yang berarti sangat signifikan. Hal ini menunjukkan bahwa Ho ditolak dan Ha diterima, sehingga dapat dikatakan bahwa terdapat pengaruh yang signifikan pelayanan terhadap kepuasan masyarakat bagian haji dan umrah Kantor Kementerian Agama Kota Pekanbaru Maka secara parsial dapat diketahui bahwa variabel 
bebas faktor pelayanan $(\mathrm{X})$ berpengaruh secara signifikan terhadap kepuasan masyarakat ( $\mathrm{Y}$ ).

3) Berdasarkan hasil uji koefisien korelasi menunjukkan terdapat hubungan yang kuat pada faktor pelayanan terhadap kepuasan masyarakat bagian haji dan umrah Kantor Kementerian Agama Kota Pekanbaru dimana nilai keeratan hubungannya adalah sebesar $79 \%$.

4) Hasil uji koefisien determinasi ada pengaruh faktor pelayanan terhadap kepuasan masyarakat bagian haji dan umrah Kantor Kementerian Agama Kota Pekanbaru sebesar 62,5\%. Sedangkan sisanya sebesar $37,5 \%$ dipengaruhi oleh variabel lain yang tidak diikutsertakan dalam penelitian ini.

\section{SIMPULAN}

Berdasarkan hasil penelitian tentang pengaruh pelayanan terhadap kepuasan masyarakat bagian haji dan umrah kantor Kementerian Agama Kota Pekanbaru maka penulis dapat menyimpulkan bahwa:

1. Dari hasil uji analisis regresi sederhana menunjukkan bahwa apabila nilai variabel kualitas pelayanan meningkat maka kepuasan masyarakat akan mengalami peningkatan.

2. Berdasarkan uji parsial menunjukkan uji hipotesis Ha diterima, yakni terdapat pengaruh yang signifikan faktor pelayanan terhadap kepuasan masyarakat.

3. Dari analisis korelasi hubungan antara variabel bebas (faktor pelayanan) dengan variabel terikat (kepuasan masyarakat) memiliki hubungan yang cukup kuat. Hal ini dapat dilihat dari nilai koefisien korelasinya.

4. Dari analisis koefisien determinasi terdapat pengaruh yang besar darifaktor pelayanan terhadap kepuasan masyarakat.

\section{DAFTAR RUJUKAN}

Departemen Agama RI, Al-Quran dan Terjemahan. (2006). CV. Penerbit Fajar Mulya, Surabaya.

Homsi, Khoirul. (2018). Pengaruh Kualitas Pelayanan Terhadap Kepuasan Nasabah BMT AL-ITTIHAD Rumbai Pekanbaru, Skripsi, Fakultas Agama Islam Universitas Islam Riau.

Lupiyadi, Rambat dan Hamdani. (2006). Manajeman Pemasaran Jasa, Selamba Empat, Jakarta Selatan.

Maulidiah, Sri. (2014). Pelayanan Publik, CV Indah Prahasta. Bandung.

Nina, Rahmayanti. (2013). Manajemen Pelayanan Prima, Graha Ilmu, Yogyakarta.

Ratminto \& Winarsih Atik Septi. (2013). Manajemen Pelayanan, Pustaka Pelajar, Yogyakarta.

Rauf, Rahyunir \& Munaf Yusri. (2015). Lembaga Kemasyarakatan Di Indonesia, Zanafa Puplishing, Yogyakarta.

Riduwan. (2009). Dasar-Dasar Statistika, CV. Alfabeta, Bandung.

Roslena, Pengaruh Pelayanan Karyawan Terhadap kepuasan Nasabah Pada PT Pegadaian (persero) Syariah Unit Tanah Merah Cabang Pegadaian Soebrantas, Skripsi, Fakultas Agama Islam Universitas Islam Riau

Samodra, Wibawa. (2009). Adminitrasi Negara Isu-isu Kontemporer, Graha Ilmu, Yogyakarta.

Sanusi, Anwar. (2016). Metodologi Penelitian Bisnis, Salemba Empat, Jakarta.

Sujiptono, Fandy. (2008). Strategi Pemasaran, CV. Andi Offset, Yokyakarta. 
Supranto. (2011). Pengukuran Tingkat Kepuasan Pelanggan, PT. Rineka Cipta, Jakarta.

Suriani Lilis dan Safri Indra. (2013). Analisis Pelaksanaan Tugas Dan Fungsi Pelayanan Sosial Pada Dinas Sosial Kabupaten Rokan Hulu, Jurnal Ilmuilmu sosial Vol. 6, p. 1

Syafiie, Inu Kencana. (2013). Sistem Administrasi Negara Republik Indinesia (SANTRI), PT Bumi Aksara, Bandung

Yusa Ahmad Tarmizi. (2010). Good Governance Pelayanan Publik pemerintah Daerah (Sebuah Orientasi Reformasi Borokrasi), Jurnal Ilmu-ilmu sosial Vol. 3, p. 2

Yussa, Tarmizi dan Andry Hendry. (2015). Prilaku dan Etika Adminitrasi Publik, Marpoyan Tujuh, P ekanbaru.

Zulkifli. (2018). Pengaruh Pelayanan Kariawan Terhadap Kepuasan Nasabah Pada PT Pegadaian (persero) Syariah Unit Tanah Merah Cabang Pegadaian Soebrantas, Syarikat : Jurnal Rumpun Ekonomi Syariah, Vol 1,P.1 